\title{
APRESENTAÇÃO \\ UM TANTO DE LINHA MESTRA LEITURAS E ESCRITAS NO PAPEL, EM CENA, NA TELA, NO RÁDIO
}

Rosana Baptistella ${ }^{1}$

A Revista Linha Mestra número 43 é uma edição atemática, composta por artigos e ensaios recebidos em fluxo contínuo. A grande maioria não trata de questões do ensino remoto, uma vez que foram escritos antes desse período pandêmico. No entanto, importante destacar que em 2020, além das três edições anuais, que trouxeram os dossiês n. $40^{2}$, n. $41^{3}$ e n. $42^{4}$, foi publicada também uma edição especial, a $41 \mathrm{~A}^{5}$, um dossiê com textos científicos e poéticos, escritos por autores de diversas áreas do conhecimento, tratando essencialmente do tema da pandemia e do isolamento social, bem como um suplemento, uma revista de artista, tendo a pausa provocada pela pandemia como mote.

Em relação à atual edição, não tendo um tema definido, coube a mim, organizadora desta edição, encontrar uma sequência, um encadeamento que pareça coerente, que forneça algum fluxo de leitura - ou não, afinal os artigos podem ser acessados individualmente. No entanto, sendo uma revista de uma associação de leitura, senti-me provocada a buscar uma narrativa que permeie os textos e que, na sequência da edição completa, proponha um diálogo entre eles.

Um ponto inegável de contato é o fato de as autoras e os autores dos artigos e ensaios aqui publicados trazerem questionamentos, reflexões e proposições para a educação, cada vez mais e mais atacada em nosso país, propiciando debates profundos e necessários sobre a leitura. Os textos referem-se às diferenças, à inclusão, à arte - em especial a literatura, o cinema, a dança e a poesia - na educação, dentro e fora da escola.

Estudada por pesquisadores de diferentes campos do conhecimento, a leitura se encontra em abordagens que ora se cruzam, ora se complementam, ora entram em confronto. $\mathrm{O}$ foco pode estar nos polos da produção, da recepção, no escritor, no editor, no leitor, nos usos e práticas, nos gêneros, no suporte, na linguagem, assim como entre lugares, em zonas fronteiriças.

\footnotetext{
${ }^{1}$ Universidade Estadual de Mato Grosso do Sul, Campo Grande, MS, Brasil.

${ }^{2}$ Dossiê organizado pela Profa. Dra. Norma Sandra de Almeida Ferreira, coordenadora naquele momento do grupo de pesquisa ALLE/AULA - Alfabetização, Leitura e Escrita e Trabalho Docente na Formação Inicial UNICAMP/CNPq. Os artigos, com discussões em torno dos temas de práticas e apropriações, objetos de leitura impressos ou digitais, projetos e programas no campo das políticas públicas foram escritos por pesquisadores vinculados a esse grupo. A imagem da capa, "Amerika", é de Jorge Méndez Blake.

${ }^{3}$ Este dossiê reuniu e publicou artigos referentes à seleção de comunicações orais e performances apresentadas no VIII Seminário Conexões: "Deleuze e Corpo e Cena e Máquina e...”, e I Encontro "Deleuze e Educação e Matemática e...", que aconteceram em novembro de 2019, tendo como coeditores convidados os pesquisadores Marcelo Vicentin, Mirele Corrêa e Alan Caballero, que participaram também da organização do evento. Arte da capa: Gustavo Torrezan.

${ }^{4}$ Organizado por Mônica Castagna Molina e Rosineide Magalhães de Sousa, professoras associadas da Universidade de Brasília (UnB), que selecionaram os artigos contemplando instituições de diferentes regiões do Brasil que oferecem o curso de Licenciatura em Educação do Campo (LEdoC), publicamos o dossiê intitulado "Licenciaturas em Educação do Campo e Letramentos Múltiplos: Formação Docente e Pesquisa". Capa: obra do artista Gildásio Jardim.

5 A edição especial foi pensada e elaborada, do início ao fim, relacionada à pandemia, publicando o dossiê: "Pandemia \& Sobrevivência - Leituras para tempos difíceis", organizado pelos convidados Alexandro Paixão e Ana Archangelo, docentes da Faculdade de Educação da Unicamp, composto por artigos escritos com muita sensibilidade por autores que atuam em campos diversos. Como suplemento, a revista "Pausa na Rede - expressões artísticas em tempos de pandemia", com resultados de uma convocatória organizada por grupos de pesquisa da Universidade Federal do Tocantins. Arte da capa: Ricardo Ribeiro Malveira.
} 
A leitura, seja de textos escritos por palavras ou por imagens, movimentos, sons, oralidades, traz à tona o repertório do leitor, que referencia leituras anteriores. "Ler será, portanto, fazer emergir a biblioteca vivida, quer dizer, a memória de leituras anteriores e de dados culturais" (GOULEMOT, 2011, p. 113). A ideia de biblioteca pessoal como um acervo de experiências que pode ter representação em diferentes materialidades, como livros, outros suportes e outras linguagens.

A atividade leitora apresenta (...) todos os traços de uma produção silenciosa: flutuação através da página, metamorfose do texto pelo olho que viaja, improvisação e expectação de significados induzidos de certas palavras, intersecções de espaços escritos, dança efêmera. (CERTEAU, 2014, p. 49.)

Nesta edição, múltiplas escritas são apresentadas: resultados de pesquisas na escola, na educação básica; no ensino superior, com iniciação científica; na pós-graduação, nos níveis de mestrado, doutorado e pós-doutorado e pesquisas de artistas independentes sobre suas obras. Esse conjunto diverso possibilita também múltiplas leituras.

A seguir, apresento os oito artigos e os três ensaios desta edição, convidando nossas leitoras e nossos leitores a dar sentido a esta publicação, considerando que “(...) o texto só tem sentido graças a seus leitores; muda com eles; ordena-se conforme códigos de percepção que lhe escapam" (CERTEAU, 2014, p. 242).

O artigo "A categoria dialética essência e aparência no ensino de estratégias de compreensão leitora", das autoras Letícia Vidigal e Sandra A. P. Franco refere-se a um estudo sobre práticas pedagógicas para a formação do sujeito leitor, desenvolvido com estudantes do $5^{\circ}$ ano da Educação Básica de uma escola pública. A obra literária eleita para discutir essência e aparência com esses estudantes foi "Pandolfo Bereba", de Eva Furnari, por possibilitar, com ludicidade, a discussão desejada. A importância fundamental da professora-pesquisadora como mediadora no processo é destacada, evidenciando o papel do professor, o que é muito positivo nesses tempos em que se discute educação domiciliar, e em que são disseminados tantos cursos com aulas pré-gravadas na educação formal, entre outras questões que colaboram com uma crescente desvalorização desse profissional (ou: de nossa profissão).

"Arquivo Escrileituras: modos de ler e escrever" reflete sobre um dos arquivos produzidos por um projeto desenvolvido por quatro universidades, integrando o Observatório da Educação e envolvendo docentes, alunos da educação básica, graduandos, mestrandos e doutorandos. As autoras concluem que "(...) é possível afirmar a prevalência dos signos das artes nos procedimentos inventivos, a fim propiciar o surgimento de uma escrita potente". Autoria de Karen E. R. Nodari, Fabiane Olegário e Sandra Mara Corazza (in memoriam); nossas homenagens à Profa. Sandra Mara Corazza e nossos sentimentos a seus familiares, amigos e colegas de trabalho.

Resultado parcial da pesquisa de pós-doutorado em andamento de Maria de Fátima Xavier da A. de Almeida, com a supervisão de Norma Sandra de A. Ferreira, temos o artigo "Estudos da leitura no livro didático de língua portuguesa dos anos iniciais do ensino fundamental". A autora nos apresenta, com muito rigor, um mapeamento de pesquisas de pós-graduação em Educação e Letras sobre o livro didático de língua portuguesa de uma determinada coleção, visando compreender práticas e representações de leitura construídas e significadas por esses objetos. Destacamos o indício que a pesquisa levanta sobre a escassez de estudos sobre o suporte, a materialidade desses objetos - livros didáticos - na comunidade à qual ele é destinado: a escola.

Com uma abordagem narrativa, a partir de uma experiência de um dos autores, costurada com fundamentos teóricos, os autores Daniel Novaes, Carlos R. da Silveira e Marcia Aparecida A. Mascia desenvolvem uma reflexão sobre inclusão escolar de crianças 
com transtorno do espectro autista, em "A educação contemporânea: um (des) caso pensado sobre inclusão", um texto que se movimenta ora em primeira pessoa do singular, ora em primeira pessoa do plural. Os autores questionam a hegemonia da tecnologia em detrimento das relações afetivas, do gesto, do toque, do olhar, afirmando que essa falta fragiliza a educação inclusiva, a que abraça - ou pretende abraçar - todas e todos.

O autor Jhonathas A. Assis Ramos aborda diferenças entre inclusão e integração escolar, apresentando estes conceitos de uma forma bem delineada em seu texto "Desafios cotidianos: em busca de uma escola inclusiva". Afirma que há muitas crianças e jovens com deficiência fora da escola na atualidade e propõe formas de ajudar os estudantes com deficiência, exemplificando a partir do deficiente visual, ao mesmo tempo em que defende que as escolas, em seus vários aspectos, teriam que se adequar para abarcar as particularidades que cada estudante, com deficiência ou não, demanda.

A dança, quando inserida na escola, geralmente tem um espaço bastante restrito. E a dança inclusiva? Que leitura é feita dos corpos diferentes, desses sujeitos quase sempre marginalizados, para incluí-los nas aulas de dança na educação formal? O artigo "Revisão de literatura sobre a dança para estudantes com deficiência", de Marcus Vinícius S. Perez e de sua orientadora, Profa. Christiane G. Araújo, traz resultados de uma pesquisa minuciosa delimitado um campo espacial e temporal - sobre inclusão na dança educação. $\mathrm{O}$ autor e a autora apresentam a proposta de um processo de ensino-aprendizagem que parta dos alunos com deficiência e que seja adaptado aos demais, pensando planos de aula que tenham como foco a inclusão no contexto escolar, visando, para esses alunos, o desenvolvimento de uma identidade corporal e descobertas de outras maneiras de comunicação corporal com o mundo.

Em "Errar a palavra, exercitar o silêncio, ou, talvez, o que dele pode escapar?", parte do resultado de um mestrado em Artes Visuais; Ronaldo Luís Campello e sua orientadora, Profa. Ursula Silva da Rosa, nos provocam a pensar a escrita como cuidado, como escuta e como resistência, nos convidando à leitura de seu texto através da cartografia, o que nomearam como um caminho-texto, trilhado por um professor-pesquisador-poeta-andarilho.

O texto "Sombra, Luz, Ação! experimentações e potências do cinema na educação infantil", de Juliana Pereira da Silva de Oliveira e Wenceslao Machado de Oliveira Jr., é uma das produções do Projeto "Lugar-escola e cinema: afetos e metamorfoses mútuas" junto ao Cineclube Regente/Cha. Os autores, logo no início do texto, nos apresentam as implicações em relação ao lugar onde o projeto se desenvolve, uma escola de Educação Infantil, com sua rotina muito bem definida, sendo também um espaço privilegiado e propício à magia e à poesia. São relatadas duas experiências, numa escrita saborosa que nos traz imagens, sons, cheiros e sensações, permeada ainda por fotografias das crianças experimentando luzes e sombras.

Na seção ensaios, temos três escritas sobre processos artísticos e de pesquisa:

Poético e metafórico, com seus meandros e curvas, " O rio da pesquisa ", de Allan Hoffmann, nos fala de vida, essência, caminhos, permeando a pesquisa, a ciência, a política, sem fixar-se, mas seguindo um fluxo em sua narrativa, apresentando poeticamente sua pesquisa e suas reflexões, o que nos convida à contemplação.

O segundo ensaio, desvinculado de pesquisa acadêmica, é resultado de um desejo do autor em traduzir uma história que ouviu ser contada numa rádio neozelandesa. A partir dessa tradução, no texto "Fui um tradutor ou um traidor? Tradução de uma história neozelandesa rimada e uma pequena reflexão sobre tradução literária", Rogério Migliorini realiza diversas relações e reflexões entre acontecimentos, globalização, linguagem, arte. Ao final, nos presenteia com a história original e a realização de sua sonora e saborosa tradução.

Intitulado "0 (zero)", o ensaio de Letícia Rodrigues descreve as subjetividades de sua dança de mesmo nome, criada a partir de questões autobiográficas. A leitura que faz de seu 
corpo, nesse processo de criação, traz questionamentos como: o que é o limite para o corpo que dança? Após uma breve, porém profunda reflexão em texto escrito, a autora nos apresenta um texto imagético, composto por oito fotografias desse espetáculo, que recebeu o VII Prêmio Denilto Gomes de Dança na categoria "Revelação"(2019), bem como o ProAC Produção de Espetáculo Inédito e Temporada de Dança (2018). É ela também quem nos fornece a imagem para a capa deste número; nossos agradecimentos a ela e a wrzaratini, autor das fotografias.

Assim, este número da Linha Mestra encerra-se como se abriu, com imagens de dança na capa e na última página. Nesses tempos pandêmicos, em que tudo parece pausar - algumas vezes de forma muito bem-vinda, é preciso afirmar -, faz-se tão necessário também o movimento, os fluxos, os ciclos que se completam, se fecham ou reiniciam, o que nos remete ao símbolo ouroboros, "a cobra mordendo o próprio rabo". Entre tantos campos pelos quais poderíamos abordar essa imagem, ficamos com a literatura, na dimensão simbólica do retorno para casa:

O círculo se fechou, a cobra mordeu o rabo: eu acabei voltando para a Soledade. Voltava sozinha, voltava de vez. E era diferente. (QUEIROZ, 2004, p. 402).

Pretendemos ter alcançado um fluxo entre os artigos e ensaios aqui publicados. Boa leitura!

\section{Referências}

CERTEAU, Michel de. A invenção do cotidiano. 1: Artes de fazer. Petrópolis, RJ: Vozes, 2014.

GOULEMOT, Jean Marie. O amor às bibliotecas. São Paulo: Editora UNESP, 2011.

QUEIROZ, Rachel de. Dôra, Doralina. Rio de Janeiro: José Olympio, 2004.

\section{Sobre a autora}

Rosana Baptistella. Doutora e Mestra em Educação (Universidade Estadual de Campinas UNICAMP), na linha de pesquisa Linguagem e Arte na Educação, Bacharel e Licenciada em Dança (Universidade Estadual de Campinas - UNICAMP). Docente efetiva da Universidade Estadual de Mato Grosso do Sul (UEMS), nos cursos de Dança e Teatro; coordenadora do Projeto de Pesquisa Corporivivências - memória, leitura e dança. Vice-líder do GPPED - Grupo de Pesquisa: Poéticas e Educação em Dança (UEMS-CNPq), coordenadora da linha de pesquisa Corpo, Leitura e Memória. Pesquisadora vinculada aos grupos ALLE/ AULA - Alfabetização, Leitura e Escrita/ Trabalho Docente na Formação Inicial (UNICAMP-CNPq) e Processos de Criação: Arte e Loucura (UFPel-CNPq).

E-mail: rosana.baptistella@uems.br. 